\title{
Activation of the $\delta$-opioid receptor inhibits serum deprivation-induced apoptosis of human liver cells via the activation of PKC and the mitochondrial pathway
}

\author{
BO TANG ${ }^{1}$, YI ZHANG ${ }^{1}$, RUI LIANG ${ }^{1}$, PENG YUAN $^{2}$, JIAN DU $^{3}$, HONGXIN WANG $^{4}$ and LIMING WANG ${ }^{1}$ \\ ${ }^{1}$ Department of General Surgery, The Second Affiliated Hospital of Dalian Medical University, Dalian 116027; \\ ${ }^{2}$ Department of Anatomy, Tianjin Medical College, Tianjin 300222; ${ }^{3}$ Department of General Surgery, \\ The First Affiliated Hospital of Dalian Medical University, Dalian 116011; ${ }^{4}$ Key Laboratory of Cell \\ Biology and Drug Research, Liaoning Medical University, Jinzhou 121001, P.R. China
}

Received June 27, 2011; Accepted August 8, 2011

DOI: 10.3892/ijmm.2011.784

\begin{abstract}
Apoptosis of human liver cells is commonly found in liver diseases and liver surgery and directly affects their prognosis. Recent studies have found that $\delta$-opioid receptors, abundant in the membranes of hepatic cells, participate in the oncogenesis and progression of liver tumors, viral hepatitis, liver cirrhosis and other diseases. The purpose of this study was to analyze the effect of the activation of the $\delta$-opioid receptor on liver cell apoptosis and explore its relationship with PKC and the mitochondrial pathway. Hepatic cells were serum-deprived to induce apoptosis in vitro. During the period of apoptosis, mitochondrial membrane potential decreased, protein levels of cytosolic cytochrome $\mathrm{c}$ increased and the expression of Bcl-2 decreased, indicating that apoptosis was specifically induced by the mitochondrial pathway. Importantly, activation of $\delta$-opioid receptors reversed the apoptotic state of hepatic cells. Following $\delta$-opioid receptor activation, the mitochondrial membrane potential remained stable, and the expression of cytosolic cytochrome $\mathrm{c}$ and Bax decreased. These data suggest that $\delta$-opioid receptor activation specifically inhibits the mitochondrial apoptotic pathway. In addition, activation of the $\delta$-opioid receptor apparently increased the levels of PKC; blocking the PKC pathway led to increased apoptosis of liver cells, which was not affected by
\end{abstract}

Correspondence to: Dr Liming Wang, Department of General Surgery, The Second Affiliated Hospital of Dalian Medical University, No. 467 Zhongshan Road, Dalian 116027, P.R. China

E-mail: wangbcc259@yahoo.com.cn

Dr Hongxin Wang, Key Laboratory of Cell Biology and Drug Research, Liaoning Medical University, No. 480 Songpo Road, Jinzhou 121001, P.R. China

E-mail: jyhxwang@163.com

Key words: $\delta$-opioid receptor, serum-free culture, human liver cells, cell apoptosis, mitochondria, protein kinase $\mathrm{C}$ the activation of $\delta$-opioid receptor. Blocking the PKC pathway led to increased apoptosis of liver cells, which was associated with $\delta$-opioid receptor activation. Therefore, the PKC pathway is involved in the anti-apoptotic effects of the $\delta$-opioid receptor on liver cells.

\section{Introduction}

Liver cell apoptosis plays an important part in the regulation of normal liver function, which is mediated by a number of signal transduction pathways (1). Yet, apoptosis serves as the cytological basis for the generation of many liver diseases (2-4). Therefore, reducing non-physiological apoptosis in hepatocytes has important clinical significance for protecting hepatic structure and function.

$\delta$-opioid receptor belongs to the superfamily of opioid receptors, which are widely expressed throughout the human body. Studies have found that the agonist of the $\delta$-opioid receptor stimulates the proliferation of neonatal rat cardiac myocytes (5) and mimics the protective effects of ischemic preconditioning on heart and brain tissue $(6,7)$. These findings have demonstrated that the $\delta$-opioid receptor plays a significant role in the growth and maintenance of cells. In addition to the central nervous system and heart, $\delta$-opioid receptors are abundantly expressed in the liver $(8,9)$. It has been recently discovered that the $\delta$-opioid receptor affects the generation and progression of hepatic tumors, viral hepatitis, liver cirrhosis and other diseases $(10,11)$.

Ischemia and hypoxia are the most commonly used methods to induce apoptosis of in vitro cultured cells (12). In this study, serum was removed from cell culture medium, and cells were grown in serum-free conditions for specified periods of time. The lack of growth factors in medium causes cells to undergo apoptosis $(13,14)$. This cellular apoptosis model closely mimics the physiologic state of ischemia and hypoxia in the liver. Cellular apoptosis occurs mainly through two pathways: the death receptor pathway and the mitochondrial pathway (15). The mitochondrial apoptotic pathway is initiated by altered mitochondrial structure and function, particularly the decline of the mitochondrial transmembrane potential. Cytochrome $\mathrm{c}$ 
is then abundantly released from mitochondria to trigger a large apoptotic protease cascade, which ultimately activates caspase-3 and leads to the apoptosis of cells. Studies have shown that the $\delta$-opioid receptor mediates protective effects on myocardial and nerve cells through inhibition of the mitochondrial apoptotic pathway $(16,17)$. In this study, we found that serum deprivation induced apoptosis of human liver cells through the mitochondrial pathway. Therefore, it is questionable whether the anti-apoptotic effect of the $\delta$-opioid receptor on liver cells is associated with the mitochondrial pathway.

Protein kinase $\mathrm{C}$ (PKC) is a large class of threonine kinases widely expressed in human cells. In the resting state, intracellular PKC is localized in the cytoplasm in the inactive form. Following stimulation by external factors, PKC translocates from the cytoplasm to the plasma membrane to become activated. The PKC signaling pathway is implicated in a wide range of biological activities and specifically mediates the proliferation and differentiation of a variety of cells. Studies have found that $\mathrm{PKC}$ is involved in the preconditioning protection of hepatic ischemia (18). The proliferation and apoptosis of normal cells and hepatic tumor cells closely correlate with PKC (19-22). Recent findings have shown that opioid receptors share a common pathway with the phosphorylation of PKC. In an isolated heart model, the cardioprotective effects of morphine were blocked by the PKC inhibitor, chelerythrine, (23), indicating that PKC mediates the pretreatment protective effect of morphine. Therefore, the intracellular signal transduction pathways activated by the stimulation of opioid receptors include the PLC-PKC pathway, the PTX-sensitive G protein-PLC-IP3-Ca ${ }^{2+}$ pathway and the AC-cAMP pathway.

In the present research, using in vitro cultured human liver cells, serum deprivation as a condition was adopted to induce the apoptosis of liver cells in order to investigate the effects of the $\delta$-opioid receptor on the apoptosis of human liver cells and its relationship with PKC and the mitochondrial pathway.

\section{Materials and methods}

Materials. Surgically resected human liver tissues were provided by the Third Department of General Surgery, The Second Affiliated Hospital of Dalian Medical University, and approval was obtained from the ethics committee. Materials used included the following: DADLE, Naltrindole, GF109203X and I, IV collagenase and Dulbecco's modified Eagle's medium (DMEM) (Sigma, USA); fetal bovine serum (Gibco, USA); MTT (Sigma); the Annexin V-FITC kit (BioRad, Hercules, CA, USA); PKC, Bcl-2 and Bax antibodies (Santa Cruz Biotechnology); and the cytochrome c and caspase-3 antibodies (Cell Signaling).

Isolation and culture of human liver cells. Human liver tissues were obtained from 14 male patients with partial hepatectomy, as approved by the ethics committee. Human hepatocytes were isolated using a modified two-step EGTA/collagenase perfusion procedure as described previously (24,25). The viability of the isolated hepatocytes was determined by trypan blue exclusion. Cell suspensions with more than $85 \%$ viability were plated and cultured for further experiments. The cells were grown uniformly and seeded in $25 \mathrm{~cm}^{2}$ flasks at the density of $1 \times 10^{6} / 1$ and then maintained in culture containing
$95 \% \mathrm{O}_{2}$ and $5 \% \mathrm{CO}_{2}$. The culture medium consisted of $15 \%$ heat-inactivated fetal bovine serum, 84\% DMEM and 1\% penicillin-streptomycin solution.

Experimental treatments. Human liver cells were cultured for $48 \mathrm{~h}$, and the medium of each group apart from the control group was replaced with serum-free DMEM and cultured further. The cells were collected at different time points $(0,24$, $48 \mathrm{~h}$ ) for analysis. During serum deprivation, the intervention groups were treated with different concentrations of DADLE $(0.01,0.1,1.0$ and $10 \mu \mathrm{M})$ and the PKC antagonist GF109203X $(10 \mu \mathrm{M})$ for $48 \mathrm{~h}$.

Cell viability. Cell viability was determined using the 3-(4,5-dimethylthiazol-2-yl)-2,5-diphenyltetrazolium bromide (MTT) assay. Human liver cells were serum-deprived for $48 \mathrm{~h}$. Thereafter, $20 \mu \mathrm{l}$ of sterile-filtered 3-(4,5-dimethylthiazol2-yl)-2,5 diphenyltetrazolium bromide stock solution $(5 \mathrm{mg} /$ $\mathrm{ml}$ ) in PBS (pH 7.4) was added to each well, and the cells were incubated for $4 \mathrm{~h}$ at $37^{\circ} \mathrm{C}$ to allow the yellow dye to be transformed into blue crystals. The unreacted dye was removed by aspiration, and $200 \mu \mathrm{l}$ of DMSO was added to each well to dissolve the dark blue crystals. Finally, the optical density was measured with a microtiter plate reader at $570 \mathrm{~nm}$. The spectrophotometer was normalized using culture medium without cells. Cell viability (\%) relative to control wells containing cell culture medium was calculated by [(A)test/(A)control]. Eight replicates were prepared for each condition.

Annexin V-FITC/PI double-labeled detection of apoptosis. The protocol was based on the use of fluorescein isothiocyanate (FITC)-conjugated Annexin V and propidium iodide (PI) staining, according to the manufacturer's instructions (Annexin V-FITC kit; Bio-Rad). Analysis by flow cytometry was carried out to differentiate the types of cell death. Cells that were Annexin V-positive and PI-negative were classified as apoptotic or early-stage apoptotic cells. Briefly, cells were digested with $0.25 \%$ trypsin, washed three or four times and then stained for 15-20 min until the cells were completely digested. After cells were digested, they were washed with PBS. Unfixed cells were stained by adding the Annexin V-FITC reaction mixture (10 $\mu \mathrm{l}$ Annexin V-FITC, $5 \mu \mathrm{l}$ propidium iodide) and incubated at room temperature for $15 \mathrm{~min}$ in the dark. The stained cells were subjected to flow cytometric analysis with a FACSCalibur (Becton-Dickinson, USA).

The isolation and purification of mitochondria. Liver cells from the different groups were collected and pre-cooled in extraction buffer $(0.2 \mathrm{M}$ mannitol, $50 \mathrm{mM}$ sucrose, $1 \mathrm{mM}$ EDTA, 1 mM EGTA, 10 mM HEPES, pH 7.4, 50 mM DTT, $5 \mathrm{mM}$ cocktail, $1 \mathrm{mM}$ PMSF) was added. Then, the cells were homogenized for 5-6 strokes and centrifuged at 1,000 x $\mathrm{g}$ for $10 \mathrm{~min}$ at $4^{\circ} \mathrm{C}$. The supernatant was collected and centrifuged at $15,000 \mathrm{x} \mathrm{g}$ for $10 \mathrm{~min}$, and the precipitate was reserved. The Nycodenz density gradient centrifugation was performed according to Sun et al (26). Finally, the mitochondria were placed in $1-2 \mathrm{ml}$ of buffer and preserved at $-80^{\circ} \mathrm{C}$.

JC-1 staining and flow cytometric analysis of mitochondrial membrane potential. After the density of the mitochondria 
isolated from the previous method was adjusted, $10 \mathrm{~g} / \mathrm{ml} \mathrm{JC}-1$ solution (dissolved with DMSO) was added, and the solution was fully mixed and incubated in a $5 \% \mathrm{CO}_{2}$ incubator in the dark for $30 \mathrm{~min}$ at $37^{\circ} \mathrm{C}$. The excess unbound dye was washed off twice with $1 \mathrm{X}$ assay buffer, and the precipitate was resuspended with PBS. The cells were analyzed by flow cytometry (BD Company, US) at an emission wavelength of $488 \mathrm{~nm}$; each sample acquired $1 \times 10^{5}$ cells. JC-1 monomers and aggregates were visualized on FL1 and FL2 detectors, respectively. As the emission of JC-1 had a dual wavelength, electronic compensation was applied to modify the overlap of the green fluorescence (monomer) and red fluorescence (polymer). FL1-H and FL2-H represented the fluorescence intensity of red and green, respectively. Quantitative analysis was performed by CellQuest Analysis software.

Protein extraction and Western blot analysis. Cells were washed once with ice-cold PBS containing $100 \mathrm{mM}$ sodium orthovanadate and solubilized in lysis buffer $(50 \mathrm{mM}$ Tris- $\mathrm{HCl}$, $137 \mathrm{mM} \mathrm{NaCl}, 10 \%$ glycerol, $100 \mathrm{mM}$ sodium orthovanadate, $1 \mathrm{mM}$ phenylmethylsulphonyl fluoride (PMSF), $10 \mathrm{mg} / \mathrm{ml}$ aprotinin, $10 \mathrm{mg} / \mathrm{ml}$ leupeptin, $1 \%$ Nonidet P-40; $\mathrm{pH}$ 7.4). After centrifugation at $12,000 \mathrm{x}$ g for $20 \mathrm{~min}$, the supernatant was collected. Cells were dissolved in sample buffer containing $65 \mathrm{mM}$ Tris- $\mathrm{HCl}$ (pH 6.8), 3\% SDS, 10\% glycerol and $6 \mathrm{M}$ urea. After determination of the protein concentration (BCA kit; Pierce, Rockford, IL, USA), $\beta$-mercaptoethanol and bromophenol blue were added to the sample buffer for electrophoresis. The protein was separated by $12 \%$ SDS-polyacrylamide gel electrophoresis (PAGE) and transblotted to polyvinylidene difluoride membranes (Bio-Rad). The blots were incubated at $4^{\circ} \mathrm{C}$ overnight with antibodies, and the resulting bands were detected using enhanced chemiluminescence. Intensities of the bands were quantified using an image-analysis system.

$R T-P C R$. Total-RNA from the cells of the different groups was prepared by using RNAiso ${ }^{\mathrm{TM}}$ Plus (Takara), and the concentration of RNA was evaluated using a spectrophotometer. The reverse transcription and PCR were performed using Takara RNA PCR kit (AMV) ver. 3.0 according to the protocols of the manufacturer. The primers for amplification were as follows: PKC, forward primer, 5'-TGAATCCTCAGTGGAATGAGT-3' and reverse primer, 5'-GGTTGCTTTCTGTCTTCTGAA-3'; $\beta$-actin, forward primer, 5'-AAGGAAGGCTGGAAGAGTGC-3' and reverse primer, 5'-CTGGGACGACATGGAGAAAA-3'. The PCR reactions were subjected to the following cycle: denaturation $\left(94^{\circ} \mathrm{C}, 30 \mathrm{sec}\right)$, annealing $\left(55^{\circ} \mathrm{C}\right.$ for $\mathrm{PKC}, 61^{\circ} \mathrm{C}$ for $\beta$-actin, $30 \mathrm{sec})$ and extension $\left(72^{\circ} \mathrm{C}, 30 \mathrm{sec}\right)$; PKC and $\beta$-actin: 29 cycles.

Statistical analysis. All data are expressed as the mean \pm SEM. To analyze the effects of drugs at different concentrations, analysis of variance (one-way ANOVA) was used. The unpaired Student's t-test was used to test for differences between two groups. A P-value $<0.05$ was considered statistically significant.

\section{Results}

The effect of serum deprivation on the apoptosis of human liver cells. Human liver cells were serum-deprived to induce apoptosis. After $24 \mathrm{~h}$ of serum deprivation, the number of adherent liver cells decreased, and the cell morphology was round and oval, which became more evident over time. Flow cytometric analysis indicated the increased apoptosis of cells over time (Fig. 1A and B). We observed an initial decline in mitochondrial potential at early time points of serum deprivation. With the prolongation of time, the mitochondrial potential decreased markedly (Fig. 1C and D). Caspase-3 is a crucial mediator of cellular apoptosis. The levels of caspase-3 increased with serum deprivation over time (Fig. 1E and F). This result indicates that serum deprivation leads to apoptosis of liver cells and that the strongest apoptotic response occurs at $48 \mathrm{~h}$. The mitochondrial pathway is the classic pathway that mediates cell apoptosis. We examined the expression of cytochrome $\mathrm{c}$ and $\mathrm{Bcl}-2$ and the changes in mitochondrial potential to determine whether the liver cell apoptosis induced by serum deprivation is mediated by the mitochondrial pathway. As the expression of cytochrome $\mathrm{c}$ in the cytoplasm apparently increased (Fig. 1G and H), the expression of Bcl-2 (Fig. 1K and L) decreased gradually. In contrast, cytochrome $\mathrm{c}$ inside the mitochondria decreased gradually (Fig. 1I and J). These results suggest that the apoptosis of human liver cells by serum deprivation occurs through the mitochondrial pathway.

The effect of $\delta$-opioid receptor activation on the apoptosis of human liver cells. Increasing concentrations of DADLE were added to the culture medium at the time when the serum was deprived. The value of A570 $\mathrm{nm}$ in human liver cells increased to varying degrees. At concentrations of DADLE over $1.0 \mu \mathrm{M}$, the value of A570 nm no longer increased. Therefore, DADLE inhibits liver cell apoptosis in a concentration-dependent manner; the most prominent effect was observed at $1.0 \mu \mathrm{M}$ (Fig. 2A). To determine the effects of $\delta$-opioid receptor activation on the apoptosis of human liver cells, $1 \mu \mathrm{M}$ of the $\delta$-opioid receptor agonist DADLE and $1 \mu \mathrm{M}$ of the $\delta$-opioid receptor antagonist Naltrindole were added to the cell culture medium when apoptosis was induced. The cells were stained with Annexin V-FITC/PI and analyzed by flow cytometry. After $48 \mathrm{~h}$ of serum deprivation, the apoptotic rate of the liver cells was $23.72 \%$, which was increased by $18.71 \%$ compared with the control group. After the $\delta$-opioid receptor was activated by DADLE, the apoptosis rate was $16.62 \%$, which was reduced by $7.1 \%$ compared with serum deprivation. When the $\delta$-opioid receptor was blocked by Naltrindole, the apoptosis rate was increased by $27.19 \%$ (Fig. 2B and C). After serum deprivation, the level of caspase- 3 rose rapidly, while after activation of the $\delta$-opioid receptor, the level of caspase- 3 tended to decline, which were blocked by Naltrindole (Fig. 2D and E). In conclusion, activation of the $\delta$-opioid receptor suppresses liver cell apoptosis induced by serum deprivation.

The activation of the $\delta$-opioid receptor inhibits apoptosis of human liver cells though the mitochondrial pathway. To verify the relationship between the protective function of the $\delta$-opioid receptor on human liver cells and the mitochondrial pathway, alterations in the mitochondrial membrane potential were detected using JC-1 dye. JC-1 dye is a highly sensitive dye which detects changes in the mitochondrial membrane potential. 
A

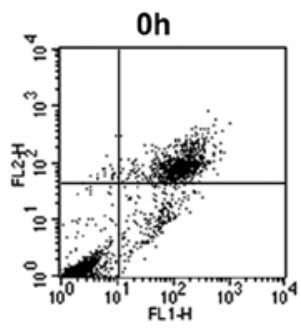

C

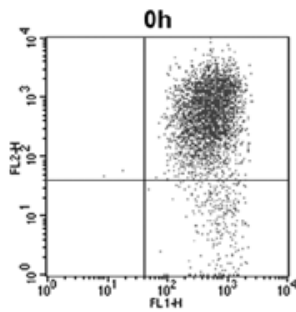

$24 \mathrm{~h}$
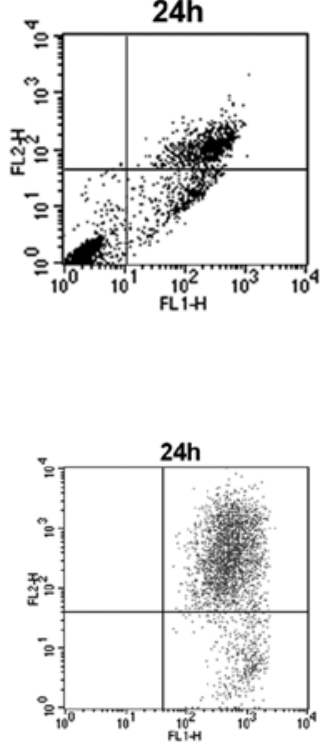
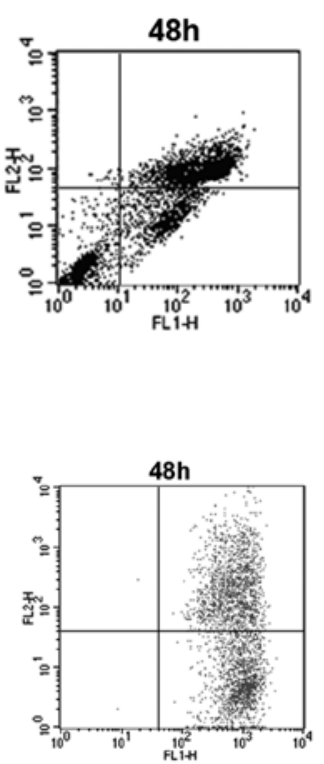

B

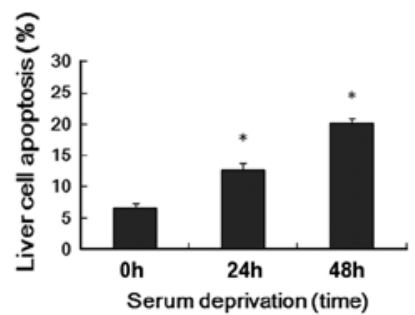

D

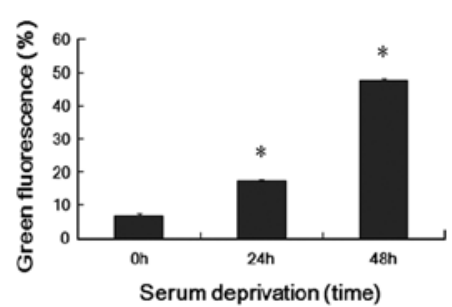

E
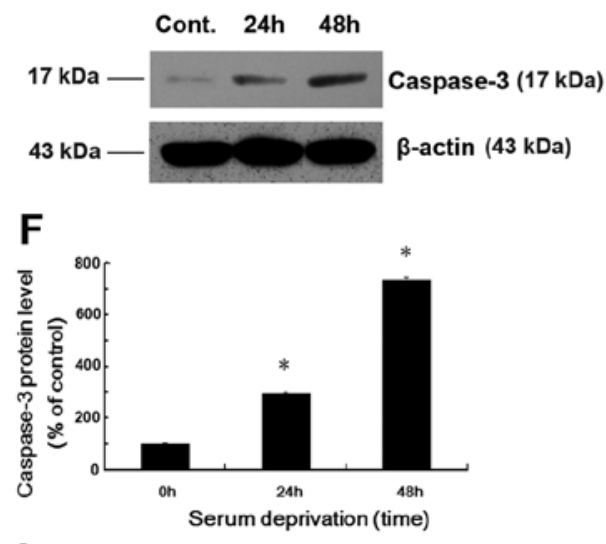

I

Mitochondria

Cont. 24h $48 \mathrm{~h}$

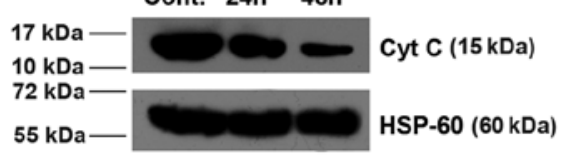

J

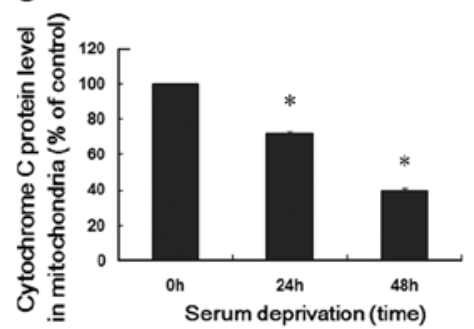

G

Cytosol

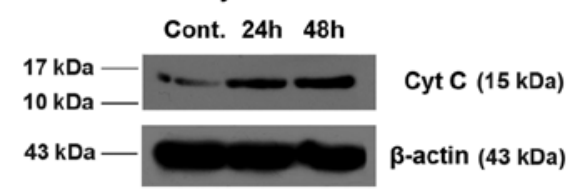

H

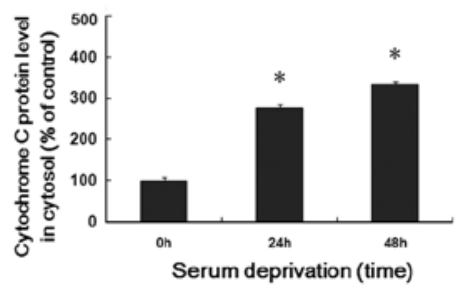

K

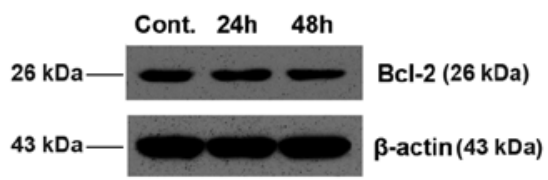

$\mathbf{L}$

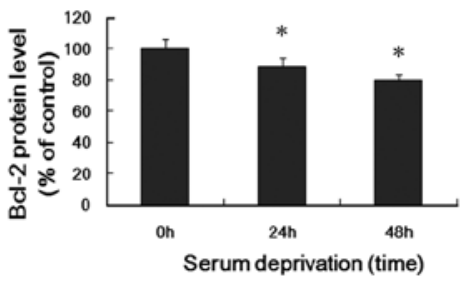

Figure 1. The effect of serum deprivation on the apoptosis of human liver cells. Human liver cells were treated with serum-free medium for different periods of time $(0,24,48 \mathrm{~h}$ ), and the levels of apoptosis were measured (A and B). The mitochondrial membrane potential with JC-1 staining was also analyzed by flow cytometry $(\mathrm{C}$ and $\mathrm{D})$. Western blot analysis was used to detect caspase-3 (E and F), cytochrome $\mathrm{c}$ in the cytoplasm $(\mathrm{G}$ and $\mathrm{H})$ and mitochondria (I and $\mathrm{J}$ ) as well as Bcl-2 (K and L) at different time points. All the data indicate that maximal apoptosis was achieved at $48 \mathrm{~h} . \mathrm{n}=6$. $\mathrm{P}<0.05$, vs. control cells.

When mitochondrial membrane potential is high, JC-1 accumulates in the matrix of mitochondria by forming $\mathrm{J}$-aggregates with red fluorescence. However, when mitochondrial membrane potential is low, JC-1 becomes a monomer with green fluorescence. In flow cytometric analysis, the lateral and longitudinal axes of coordinates represent the distribution of green and red fluorescence, respectively. The ratio of green and red fluorescence represents the depolariza- 


\section{A}

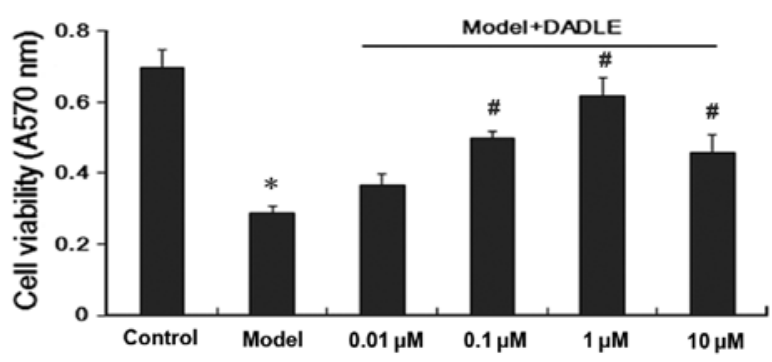

B
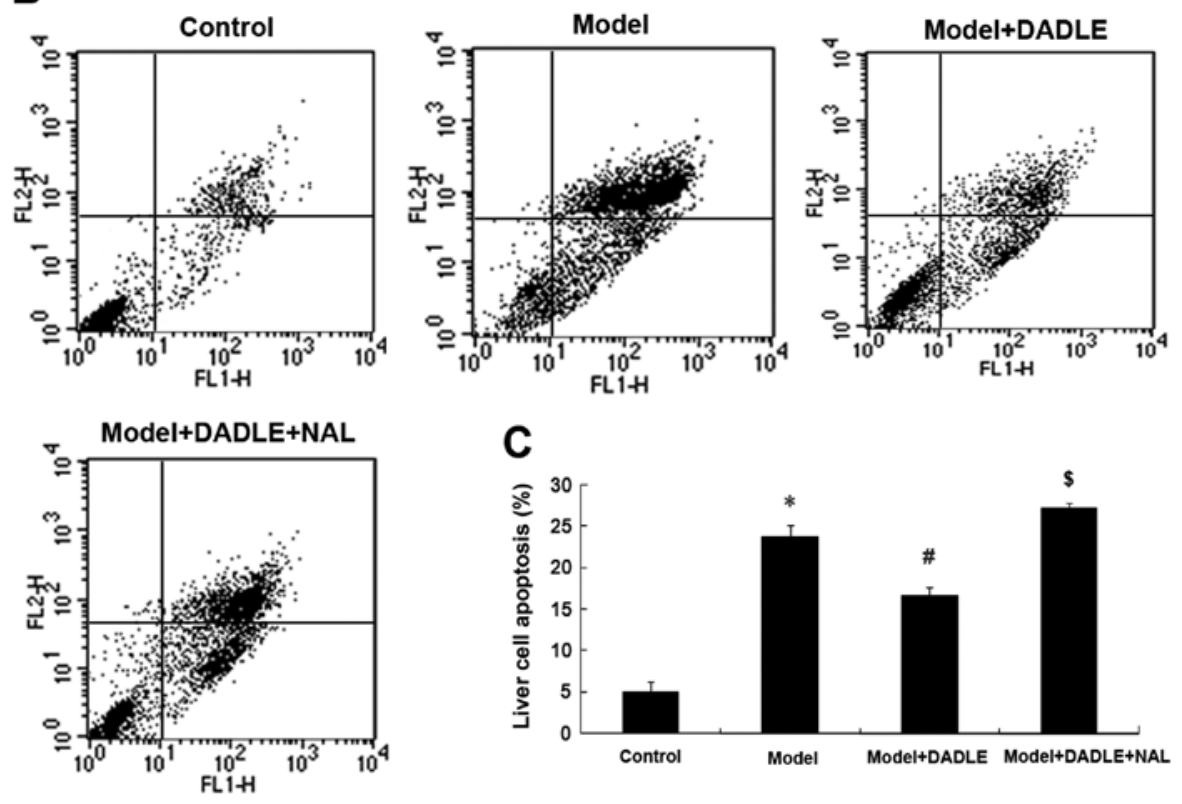

D

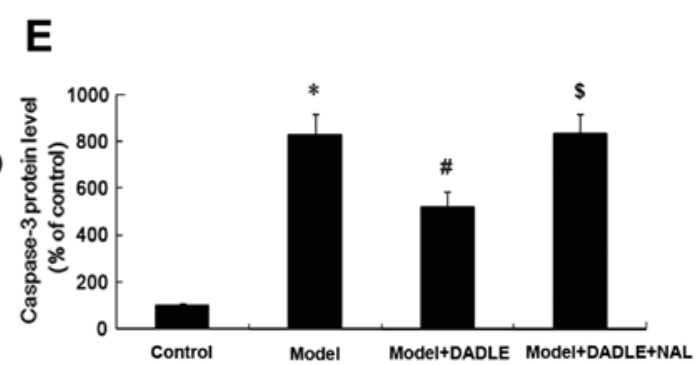

Figure 2. The effect of $\delta$-opioid receptor activation on the apoptosis of human liver cells. The agonist of the $\delta$-opioid receptor, DADLE, was added to the serum-free medium at different concentrations $(0.01,0.1,1.0$ and $10 \mu \mathrm{M})$ and incubated for $48 \mathrm{~h}$. Cell viability was determined by the MTT assay, and the maximal viability was achieved at $1.0 \mu \mathrm{M}(\mathrm{A})$. DADLE $(1.0 \mu \mathrm{M})$, the $\delta$-opioid receptor agonist, and NAL $(1.0 \mu \mathrm{M})$, the $\delta$-opioid receptor antagonist were incubated with serum-deprived liver cells for $48 \mathrm{~h}$. Flow cytometric analysis was performed to analyze the apoptotic rate of cells with Annexin V-FITC/PI staining (B and C). Western blot analysis was performed to evaluate the caspase-3 protein levels (D and E). The results reveal that DADLE plays an inhibitory role against serum deprivation-induced apoptosis, which can be reversed by NAL. $\mathrm{n}=6$. ${ }^{\mathrm{P}} \mathrm{P}<0.05$, vs. control cells; ${ }^{\text {}} \mathrm{P}<0.05$, vs. model cells; ${ }^{\mathrm{P}} \mathrm{P}<0.05$, vs. model + DADLE cells.

tion percentage of mitochondria. The data reveal that serum deprivation induces the apparent decline of mitochondrial membrane potential, and the alteration of mitochondrial membrane potential occurs earlier than cell apoptosis. When the $\delta$-opioid receptor was activated, there was no significant change in mitochondria membrane potential (Fig. 3A and B). Cytochrome $\mathrm{c}$ release into the cytoplasm is another marker of apoptosis. To investigate the function of $\delta$-opioid receptor activation on cytochrome $\mathrm{c}$ release, we analyzed the levels of cytochrome $\mathrm{c}$ in the mitochondria and cytoplasm by Western blot analysis. Compared with the levels induced by serum deprivation, the levels of cytosolic cytochrome $\mathrm{c}$ decreased with the activation of the $\delta$-opioid receptor, while the levels of mitochondrial cytochrome $\mathrm{c}$ increased (Fig. 3C-F).

Upon induction of the apoptotic signal, Bax protein translocates from the cytoplasm to insert into the outer membrane of mitochondria, which alters the permeability of the mitochondrial outer membrane to promote the release of cytochrome $\mathrm{c}$ (27). $\delta$-opioid receptor activation increased the levels of Bax protein in the cytoplasm and reduced its expression in the mito- 
A
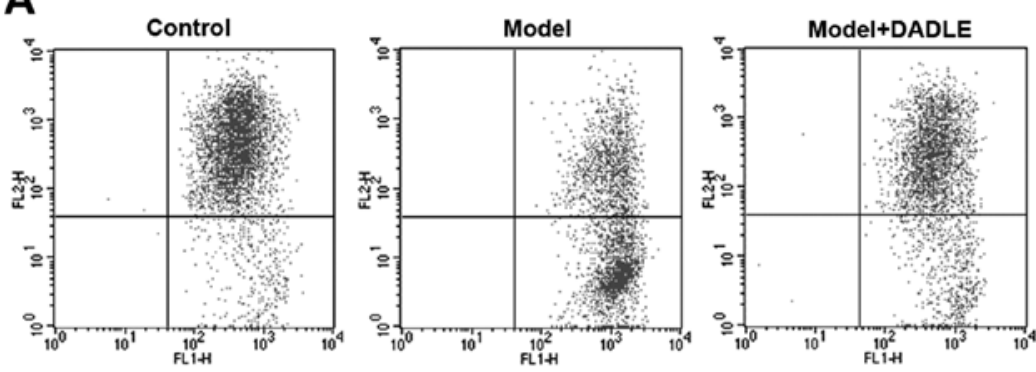

B
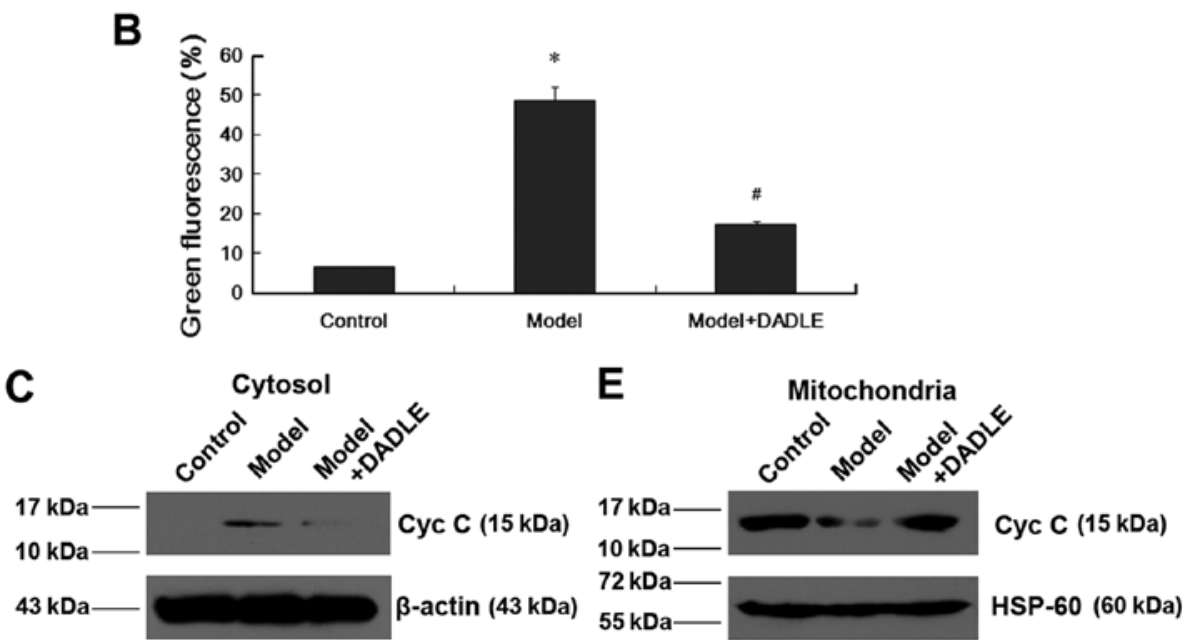

D
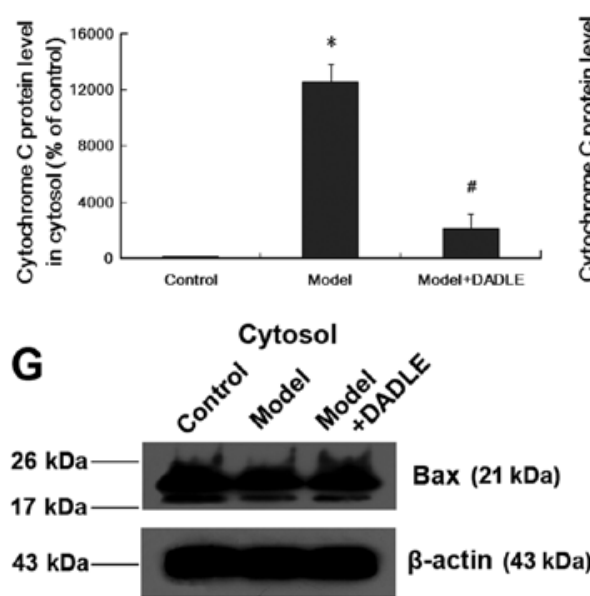

H

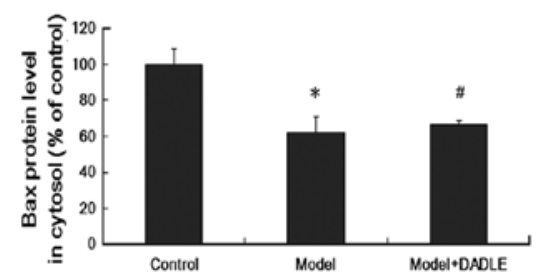

$\mathbf{F}$
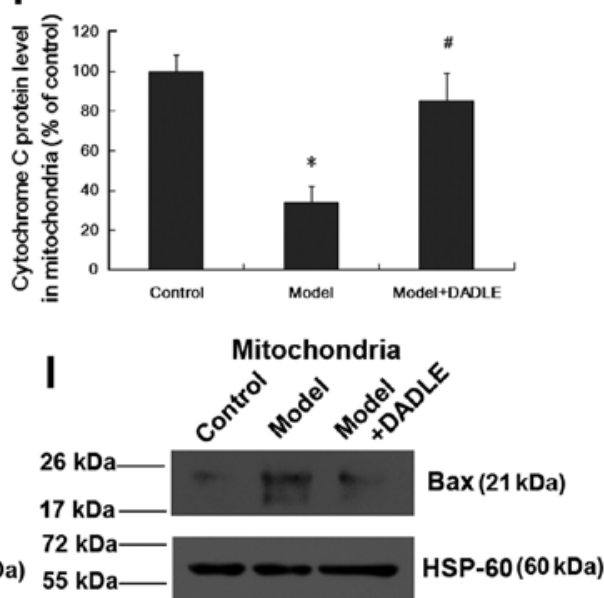

$\mathbf{J}$

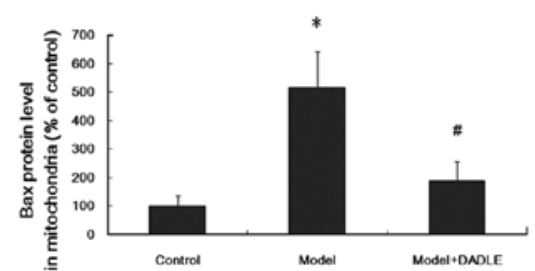

Figure 3. Activation of the $\delta$-opioid receptor inhibits apoptosis of human liver cells though the mitochondrial pathway. DADLE (1.0 $\mu \mathrm{M}$ ), the $\delta$-opioid receptor agonist, was incubated with serum-deprived liver cells for $48 \mathrm{~h}$. JC-1 dye was used to detect alterations in the mitochondrial membrane potential by flow cytometric analysis (A and B). Both cytochrome $\mathrm{c}$ and Bax in the cytoplasm and mitochondria were evaluated by Western blot analysis, and the results suggest that DADLE promotes Bax translocation from the mitochondria to the cytoplasm and reduces the release of cytochrome $\mathrm{c}$ from the mitochondria $(\mathrm{C}-\mathrm{J})$. $\mathrm{n}=6$. ${ }^{*} \mathrm{P}<0.05$, vs. control cells; ${ }^{\#} \mathrm{P}<0.05$, vs. model cells.

chondria (Fig. 3G-J). Our data revealed that DADLE activated the $\delta$-opioid receptor on the membrane of liver cells, stabilized the mitochondrial membrane potential and prevented the release of cytochrome c from mitochondria and the translocation of cytosolic Bax. In this manner, serum deprivation-induced apoptosis of human liver cells was suppressed. 

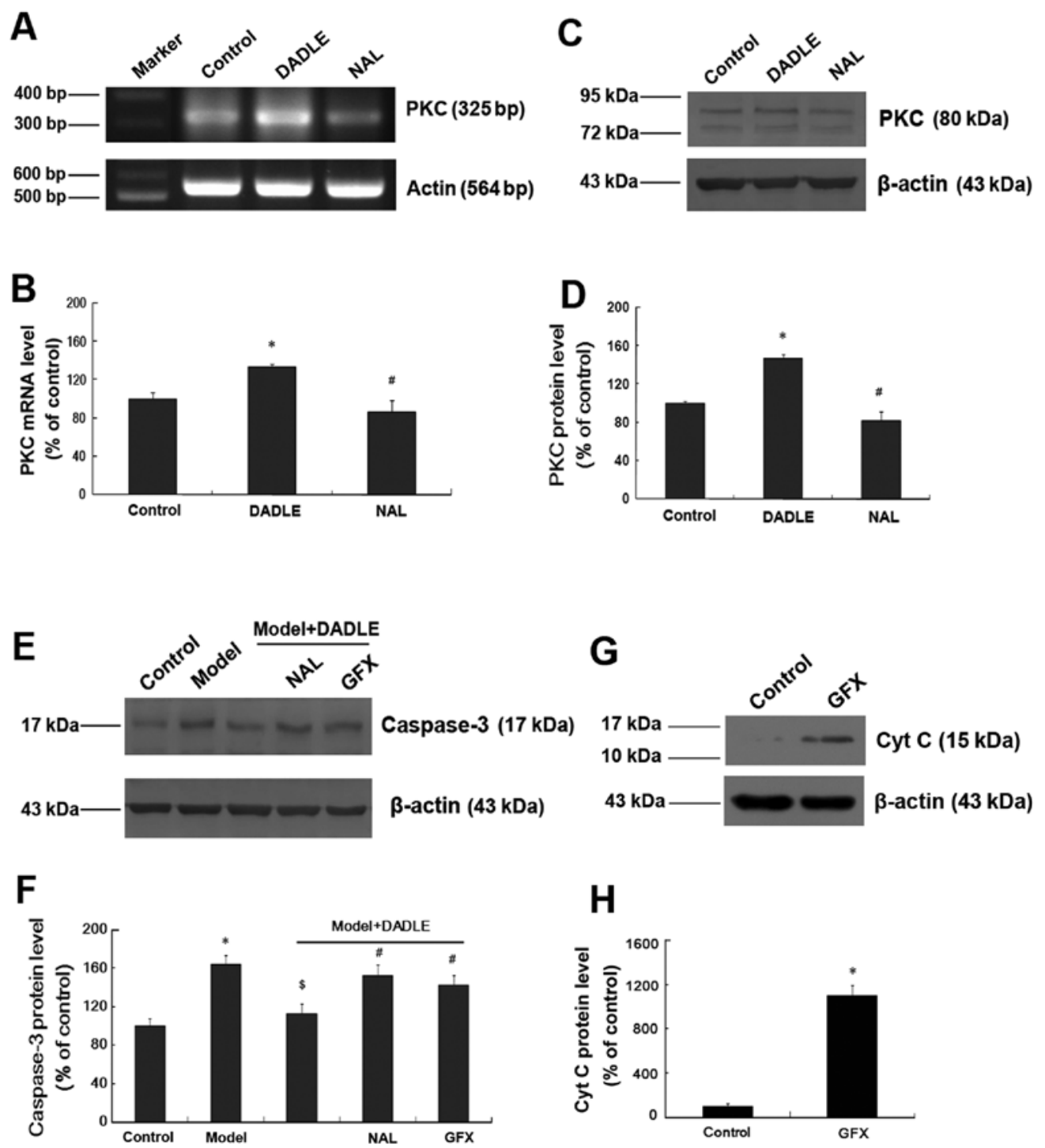

Figure 4. The function of $\delta$-opioid receptor activation in apoptosis of human liver cells under the blockade of the PKC pathway. During serum deprivation, the intervention groups were treated with DADLE $(1.0 \mu \mathrm{M})$ and the $\delta$-opioid receptor antagonist NAL $(1.0 \mu \mathrm{M})$, and RT-PCR and Western blot analysis were performed to investigate the mRNA and protein expression of PKC. PKC expression was up-regulated by DADLE and down-regulated by NAL (A-D). Caspase-3 was detected by Western blot analysis. DADLE decreased caspase-3 expression and the anti-apoptotic effect of DADLE was blocked by NAL and GF109203X (specific PKC inhibitor) (E and F). Western blot analysis showed that Cyt C increased markedly by blocking the PKC pathway with GF109203X, indicating there was a relationship between $\mathrm{PKC}$ and the mitochondrial pathway $(\mathrm{G}$ and $\mathrm{H}) . \mathrm{n}=6 .{ }^{*} \mathrm{P}<0.05$, vs. control cells; ${ }^{\$} \mathrm{P}<0.05$, vs. model cells; ${ }^{*} \mathrm{P}<0.05$, vs. model + DADLE cells.

The function of $\delta$-opioid receptor activation in the apoptosis of human liver cells under the blockade of the PKC pathway. To analyze whether the blockade of the PKC pathway affects the protective function of the $\delta$-opioid receptor on human liver cell apoptosis and whether the stimulation of $\delta$-opioid receptor activates PKC, Western blot analysis and PR-PCR were used to detect the mRNA and the protein expression of PKC. It was found that the $\delta$-opioid receptor agonist DADLE increased both mRNA and protein expression of PKC markedly (Fig. 4A-D), indicating that stimulation of the $\delta$-opioid receptor activates PKC. Moreover, these experiments demonstrated that the activation of the $\delta$-opioid receptor inhibits the apoptosis of liver cells and down-regulates the expression of caspase-3. However, when the PKC pathway was blocked, caspase- 3 expression levels increased in the presence of the activated $\delta$-opioid receptor (Fig. 4E and F), indicating that the PKC pathway mediates the anti-apoptotic function of $\delta$-opioid receptor activation. In addition, when the PKC pathway was blocked, the expression of cytochrome c was significantly increased. This indicated that there was a link between PKC and the mitochondrial pathway (Fig. $4 \mathrm{G}$ and $\mathrm{H}$ ).

\section{Discussion}

In this study, we examined the effects of $\delta$-opioid receptor activation on the apoptosis of human liver cells and explored the underlying mechanisms of protection. Apoptosis of human liver cells is an important feature of a variety of liver diseases, and it is often the cytological basis of disease occurrence. Therefore, clarifying the underlying mechanisms of apoptosis 
and reducing non-physiological levels of apoptosis in hepatocytes may have important clinical significance for protecting hepatic structure and function. It has been determined that serum deprivation triggers the accumulation of intracellular ROS and alteration of mitochondrial function, which leads to cell apoptosis (28). Serum deprivation is a commonly used method to induce cell apoptosis $(29,30)$. In this study, human liver cells exhibited apparent apoptosis after serum deprivation, and with increased time in serum-free medium, the apoptotic effect became more severe. Moreover, in the early phase of serum deprivation, the mitochondrial membrane potential declined. Afterwards, cytochrome $\mathrm{c}$ was activated and released from the mitochondria into the cytoplasm, and the expression of caspase- 3 was elevated. In conclusion, the serum deprivation-induced apoptosis of human liver cells occurs via the mitochondrial pathway.

Opioid receptors are widely expressed throughout the body, and it has been found that in addition to the central nervous system, a large number of opioid receptors are expressed in the liver. In the superfamily of opioid receptors, the $\delta$-opioid receptor is mainly associated with the survival and proliferation of cells (31). Studies have shown that the $\delta$-opioid receptor has protective functions in the liver. For example, $\delta$-opioid receptors were found to have a protective role against liver damage in an animal model of cholestasis (32). In addition, endogenous opioid growth factor promotes the proliferation of liver cancer cells (10). These protective effects are attributed to the activation of the $\delta$-opioid receptor on liver cell membranes. Our results showed that activation of the $\delta$-opioid receptor reduces the apoptosis of human liver cells and down-regulates the expression of caspase-3, which constitutes a protective mechanism to sustain the physiological function of the liver.

The inhibitory function of the $\delta$-opioid receptor against hepatic cell apoptosis is unknown, but its protective effect on myocardial cells is prominent. Yao et al (33) reported that activation of the $\delta$-opioid receptor reduces the apoptosis of myocardial cells through inhibition of the ERK and IP3 pathways. Furthermore, Huang et al (34) reported that activation of the $\delta$-opioid receptor inhibits apoptosis by promoting CGRP expression in myocardial cells. A cell-type specific discrepancy between liver cells and myocardial cells may exist. However, our findings are consistent with those of Wang et al (5), who found that activation of the $\delta$-opioid receptor inhibited the serum deprivation-induced apoptosis of cardiomyocytes from a neonatal rat; the apoptotic appearance became more prominent when the concentration reached $1.0 \mu \mathrm{M}$. Further investigations are necessary to determine whether the activation of the $\delta$-opioid receptor inhibits the apoptosis of other types of tissues and cells.

It has been confirmed that opioid receptors act through the PTX-sensitive G protein signal pathway (35) and the KATP signal pathway (36). In addition, Zhao et al (37) found that opioid receptors promote cell survival and proliferation via the ERK1/2 pathway. We determined that the activation of the $\delta$-opioid receptor enhances PKC expression. PKC stimulation inhibits the apoptosis of different types of cells (38-40). Meanwhile, PKC also participates in the protection against hepatic ischemia reperfusion injury and is involved in the processes of cellular proliferation and apoptosis $(19,41)$. We observed that despite $\delta$-opioid receptor activation, the blockade of the PKC pathway increases the apoptosis of human liver cells. We conclude that the PKC pathway is a possible signal transduction pathway involved in $\delta$-opioid receptor inhibition of human liver apoptosis induced by serum deprivation.

Our previous results demonstrated that serum deprivation induces the apoptosis of human liver cells through the mitochondrial pathway. These findings are similar to the research conducted by Li et al (42). It has been demonstrated that the $\delta$-opioid receptor agonist DADLE protects nerve cells against apoptosis through the mitochondrial pathway (43), but it remains to be determined whether this anti-apoptotic mechanism is involved in our system. After activation of the $\delta$-opioid receptor, the mitochondrial membrane potential rose markedly, the level of cytosolic cytochrome c decreased and the translocation of Bax from the cytoplasm to the mitochondria decreased, indicating that the protective effect of the $\delta$-opioid receptor on liver cells is associated with the mitochondrial pathway.

In summary, we determined that serum deprivationinduced apoptosis of human liver cells occurs through the mitochondrial pathway. Activation of the $\delta$-opioid receptor reverses the mitochondrial apoptotic pathway. Moreover, the protective function of the $\delta$-opioid receptor on human liver cells is associated with PKC and the mitochondrial pathway. The elucidation of this anti-apoptotic mechanism is important for understanding the function of the $\delta$-opioid receptor in human liver cell apoptosis and may lead to the development of therapeutics for human liver diseases.

\section{Acknowledgements}

We thank the Dalian Institute of Chemical Physics and the Chinese Academy of Sciences for the experimental supplies. This study was supported by National High Technology Research and Development Program (863 Program) funding (2006AA02A309).

\section{References}

1. Kren BT, Trembley JH, Fan G and Steer CJ: Molecular regulation of liver regeneration. Ann NY Acad Sci 831: 361-381, 1997.

2. Farinati F, Cardin R, Fiorentino M, D'errico A, Grigioni W, Cecchetto A and Naccarato R: Imbalance between cytoproliferation and apoptosis in hepatitis $\mathrm{C}$ virus-related chronic liver disease. J Viral Hepat 8: 34-40, 2001.

3. Chen W, Woodruff TK and Mayo KE: Activin A-induced HepG2 liver cell apoptosis: involvement of activin receptors and smad proteins. Endocrinology 141: 1263-1272, 2000.

4. Nakajima H, Mizuta N, Fujiwara I, Sakaguchi K, Ogata H, Magae J, Yagita H and Koji T: Blockade of the Fas/Fas ligand interaction suppresses hepatocyte apoptosis in ischemia-reperfusion rat liver. Apoptosis 13: 1013-1021, 2008.

5. Wang D, Wang H, Wu G, Yang Y, Yang J, Liu C and Wong TM: Protein kinase $\mathrm{C}$ mediates the effects of delta-opioid receptor stimulation on survival and apoptosis in neonatal cardiomyocytes cultured in serum-deprived condition. Pharmazie 64: 466-471, 2009.

6. Maslov LN, Barzakh EI, Krylatov AV, Chernysheva GA, Krieg T, Solenkova NV, Lishmanov AY, Cybulnikov SY and Zhang Y: Opioid peptide deltorphin II simulates the cardioprotective effect of ischemic preconditioning: role of $\delta$-opioid receptors, protein kinase C, and K(ATP) channels. Bull Exp Biol Med 149: 591-593, 2010

7. Wang S, Duan Y, Su D, Li W, Tan J, Yang D, Wang W, Zhao Z and Wang X: Delta opioid peptide [d-Ala2, d-Leu5] enkephalin (DADLE) triggers postconditioning against transient forebrain ischemia. Eur J Pharmacol 658: 140-144, 2011. 
8. Neidle A, Manigault I and Wajda IJ: Distribution of opiate-like substances in rat tissues. Neurochem Res 4: 399-410, 1979.

9. Zagon IS, Verderame MF, Zimmer WE and McLaughlin PJ: Molecular characterization and distribution of the opioid growth factor receptor (OGFr) in mouse. Brain Res Mol Brain Res 84: 106-114, 2000.

10. Avella DM, Kimchi ET, Donahue RN, Tagaram HR, McLaughlin PJ, Zagon IS and Staveley-O'Carroll KF: The opioid growth factor-opioid growth factor receptor axis regulates cell proliferation of human hepatocellular cancer. Am J Physiol Regul Integr Comp Physiol 298: 459-466, 2010.

11. Boyella VD, Nicastri AD and Bergasa NV: Human hepatic metenkephalin and delta opioid receptor-1 immunoreactivities in viral and autoimmune hepatitis. Ann Hepatol 7: 221-226, 2008

12. Shiva S, Sack MN, Greer JJ, Duranski M, Ringwood LA, Burwell L, Wang X, MacArthur PH, Shoja A, Raghavachari N, Calvert JW, Brookes PS, Lefer DJ and Gladwin MT: Nitrite augments tolerance to ischemia/reperfusion injury via the modulation of mitochondrial electron transfer. J Exp Med 204: 2089-2102, 2007.

13. Goyeneche AA, Harmon JM and Telleria CM: Cell death induced by serum deprivation in luteal cells involves the intrinsic pathway of apoptosis. Reproduction 131: 103-111, 2006.

14. Chen CL, Chan PC, Wang SH, Pan YR and Chen HC: Elevated expression of protein kinase $\mathrm{C}$ delta induces cell scattering upon serum deprivation. J Cell Sci 123: 2901-2913, 2010.

15. Orrenius S: Mitochondrial regulation of apoptotic cell death Toxicol Lett 149: 19-23, 2004.

16. Jang Y, Xi J, Wang H, Mueller RA, Norfleet EA and Xu Z: Postconditioning prevents reperfusion injury by activating deltaopioid receptors. Anesthesiology 108: 243-250, 2008.

17. Raut A, Iglewski M and Ratka A: Differential effects of impaired mitochondrial energy production on the function of mu and delta opioid receptors in neuronal SK-N-SH cells. Neurosci Lett 404 242-246, 2006

18. Baldanzi G, Alchera E, Imarisio C, Gaggianesi M, Dal Ponte C, Nitti M, Domenicotti C, van Blitterswijk WJ, Albano E, Graziani A and Carini R: Negative regulation of diacylglycerol kinase theta mediates adenosine-dependent hepatocyte preconditioning. Cell Death Differ 17: 1059-1068, 2010.

19. Saberi B, Shinohara M, Ybanez MD, Hanawa N, Gaarde WA Kaplowitz N and Han D: Regulation of $\mathrm{H}(2) \mathrm{O}(2)$-induced necrosis by PKC and AMP-activated kinase signaling in primary cultured hepatocytes. Am J Physiol Cell Physiol 295: C50-C63, 2008.

20. Wang Y, Schattenberg JM, Rigoli RM, Storz P and Czaja MJ Hepatocyte resistance to oxidative stress is dependent on protein kinase C-mediated down-regulation of c-Jun/AP-1. J Biol Chem 279: 1089-1097, 2004

21. Hung JH, Lu YS, Wang YC, Ma YH, Wang DS, Kulp SK, Muthusamy N, Byrd JC, Cheng AL and Chen CS: FTY720 induces apoptosis in hepatocellular carcinoma cells through activation of protein kinase C delta signaling. Cancer Res 68: 1204-1212, 2008.

22. Takai S, Matsushima-Nishiwaki R, Tokuda H, Yasuda E, Toyoda H, Kaneoka Y, Yamaguchi A, Kumada T and Kozawa O: Protein kinase $\mathrm{C}$ delta regulates the phosphorylation of heat shock protein 27 in human hepatocellular carcinoma. Life Sci 81: 585-591, 2007

23. Miki T, Cohen MV and Downey JM: Opioid receptor contributes to ischemic preconditioning through protein kinase $\mathrm{C}$ activation in rabbits. Mol Cell Biochem 186: 3-12, 1998.

24. Ryan CM, Carter EA, Jenkins RL, Sterling LM, Yarmush ML, Malt RA and Tompkins RG: Isolation and long-term culture of human hepatocytes. Surgery 113: 48-54, 1993.

25. Weiss TS, Pahernik S, Scheruebl I, Jauch KW and Thasler WE: Cellular damage to human hepatocytes through repeated application of 5-aminolevulinic acid. J Hepatol 38: 476-482, 2003.
26. Sun Q, Miao M, Jia X, Guo W, Wang L, Yao Z, Liu C and Jiao B: Subproteomic analysis of the mitochondrial proteins in rats $24 \mathrm{~h}$ after partial hepatectomy. J Cell Biochem 105: 176-184, 2008.

27. Saito M, Korsmeyer SJ and Schlesinger PH: BAX-dependent transport of cytochrome $\mathrm{c}$ reconstituted in pure liposomes. Nat Cell Biol 2: 553-555, 2000.

28. Lee SB, Kim JJ, Kim TW, Kim BS, Lee MS and Yoo YD: Serum deprivation-induced reactive oxygen species production is mediated by Romo1. Apoptosis 15: 204-218, 2010.

29. Zhuge J and Cederbaum AI: Serum deprivation-induced HepG2 cell death is potentiated by CYP2E1. Free Radic Biol Med 40: 63-74, 2006.

30. Wang YD, Yang F, Chen WD, Huang X, Lai L, Forman BM and Huang W: Farnesoid X receptor protects liver cells from apoptosis induced by serum deprivation in vitro and fasting in vivo. Mol Endocrinol 22: 1622-1632, 2008.

31. Su TP: Delta opioid peptide [D-Ala(2), D-Leu(5)] enkephalin promotes cell survival. J Biomed Sci 7: 195-199, 2000.

32. Marzioni M, Alpini G, Saccomanno S, de Minicis S, Glaser S, Francis H, Trozzi L, Venter J, Orlando F, Fava G, Candelaresi C, Macarri G and Benedetti A: Endogenous opioids modulate the growth of the biliary tree in the course of cholestasis. Gastroenterology 130: 1831-1847, 2006.

33. Yao LL, Wang YG, Cai WJ, Yao T and Zhu YC: Survivin mediates the anti-apoptotic effect of delta-opioid receptor stimulation in cardiomyocytes. J Cell Sci 120: 895-907, 2007.

34. Huang MH, Nguyen V, Wu Y, Rastogi S, Lui CY, Birnbaum Y, Wang HQ, Ware DL, Chauhan M, Garg N, Poh KK, Ye L, Omar AR, Tan HC, Uretsky BF and Fujise K: Reducing ischaemia/ reperfusion injury through delta-opioid-regulated intrinsic cardiac adrenergic cells: adrenopeptidergic co-signalling. Cardiovasc Res 84: 452-460, 2009.

35. Schultz JJ, Hsu AK and Gross GJ: Ischemic preconditioning and morphine-induced cardioprotection involve the delta (delta)-opioid receptor in the intact rat heart. J Mol Cell Cardiol 29: 2187-2195, 1997.

36. Pateliya BB, Singh N and Jaggi AS: Possible role of opioids and KATP channels in neuroprotective effect of postconditioning in mice. Biol Pharm Bull 31: 1755-1760, 2008.

37. Zhao M, Wang HX, Yang J, Su YH, Su RJ and Wong TM: deltaOpioid receptor stimulation enhances the growth of neonatal rat ventricular myocytes via the extracellular signal-regulated kinase pathway. Clin Exp Pharmacol Physiol 35: 97-102, 2008.

38. Allen TR, Krueger KD, Hunter WJ and Agrawal DK: Evidence that insulin-like growth factor-1 requires protein kinase C-epsilon, PI3-kinase and mitogen-activated protein kinase pathways to protect human vascular smooth muscle cells from apoptosis. Immunol Cell Biol 83: 651-667, 2005.

39. Agudo-López A, Miguel BG, Fernández I and Martínez AM: Role of protein kinase $\mathrm{C}$ and mitochondrial permeability transition pore in the neuroprotective effect of ceramide in ischemia-induced cell death. FEBS Lett 585: 99-103, 2011.

40. Peng Y,Hu Y, Feng N, Wang L and Wang X: L-3-n-butyl-phthalide alleviates hydrogen peroxide-induced apoptosis by $\mathrm{PKC}$ pathway in human neuroblastoma SK-N-SH cells. Naunyn Schmiedebergs Arch Pharmacol 383: 91-99, 2011.

41. Alchera E,Dal Ponte C,Imarisio C,Albano Eand Carini R: Molecular mechanisms of liver preconditioning. World J Gastroenterol 16: 6058-6067, 2010

42. Li Z, Wei H, Liu X, Hu S, Cong X and Chen X: LPA rescues ER stress-associated apoptosis in hypoxia and serum deprivationstimulated mesenchymal stem cells. J Cell Biochem 111: 811-820, 2010.

43. Tsao LI and Su TP: Hibernation-induction peptide and cell death: [D-Ala2, D-Leu5] enkephalin blocks Bax-related apoptotic processes. Eur J Pharmacol 428: 149-151, 2001. 